Counsellia: Jurnal Bimbingan dan Konseling, 10 (2), $2020 \mid 109-120$

Copyright (C2020 Universitas PGRI Madiun

ISSN: 2088-3072 (Print) / 2477-5886 (Online)

Available online at: http://e-journal.unipma.ac.id/index.php/JBK

DOI: 10.25273/counsellia.v10i2.5816.

\title{
Pengembangan modul hipno-Neuro Linguistic Programming (NLP) untuk mengatasi stage fright Mahasiswa
}

\author{
Rapikah $^{1}$, Casmini $^{2}$ \\ ${ }^{1}$ Pascasarjana, UIN Sunan Kalijaga, Yogyakarta \\ fiqah.baik@gmail.com \\ ${ }^{2}$ Fakultas Dakwah dan Komunikasi, UIN Sunan Kalijaga, Yogyakarta \\ casmini@uin-suka.ac.id
}

\begin{abstract}
Abstrak
Stage fright sebagai sebuah masalah yang sering kali dialami oleh mahasiswa baru dapat menghambat mahasiswa dalam menjalankan tugas lapangan pada proses perkuliahan dan dalam proses menyampaikan materi di dalam kelas. Dalam peneitian ini, metode penelitian yang digunakan adalah metode penelitian $R \& D$, peneliti mengembangkan sebuah panduan terapi yang menggabungkan teknik hipnosis dan Neuro Linguistic Programming (NLP) yang diujicobakan kepada Mahasiswa baru UIN Sunan Kalijaga. Hasil uji coba dari modul panduan tersebut menunjukkan bahwa satge fright dapat diminimalisir dengan hypnosis dan NLP yang dalam penelitian ini berfungsi sebagai media untuk memasukkan nilai baru kepada klien dengan menggunakan pengembangan model Hipno-NLP untuk membuat bentuk anchor baru yang bertujuan mengatasi stage fright.
\end{abstract}

Kata kunci: Hipnosis, Neuro Linguistic Programming, Stage Fright

\begin{abstract}
Stage fright as a problem that is oftentimes be experienced by new college students is obstructive in obeying assignment of study, either field assignment or presenting assignment in class. This research used Research and Development method and developed a therapeutic guide which combines hypnosis and Neuro Linguistic Programming (NLP) techniques and were tested on new students of UIN Sunan Kalijaga. The trial results of the guide module indicate that there is a significant effect on the subjects within both of these tools serve as a medium for entering new values to clients by using the development of the Hipno-NLP model to create new anchor that aim to overcome the stage fright.
\end{abstract}

Keywords: Hipnosis, Neuro Linguistic Programming, Stage Fright.

\section{PENDAHULUAN}

Stage fright merupakan salah satu bentuk stress ringan yang dapat dialami oleh setiap individu. rasmun mengungkapkan bahwa stress memiliki tiga tingkatan, stress yang masih dalam tingkatan ringan umum dirasakan oleh setiap orang dan hanya berlangsung dalam beberapa jam (Rasmun, 2004). Stress yang dimaksudkan dalam penelitian ini adalah bentuk stress ringan yang dialami mahasiswa ketika mereka harus show up di hadapan banyak orang atau disebut sebagai demam panggung atau stage fright (Mambu et al., 2019). Penelitian ini difokuskan kepada mahasiswa baru UIN Sunan Kalijaga yang 
baru berhadapan dengan bangku perkuliahan, di mana mereka sebagai mahasiswa yang selain memiliki tugas untuk membuat makalah juga memiliki tugas untuk menyampaikan makalahnya di hadapan teman-teman di kelas, bahkan di tempat umum jika tugas yang dilaksanakan berkaitan dengan lingkungan masyarakat dan organisasi.

Diperlukan keberanian agar tidak terjadi performance anxiety yang memunculkan stage fright di mana individu secara fisik mengaktifkan sistem saraf simpatetis seperti meningkatnya denyut jantung, dada berdebar-debar, berkeringat, otot menegang, tangan gemetar, atau telapak tangan dan kaki menjadi dingin (Adriansyah et al., 2015). Keberanian tersebut dapat diperoleh dengan keyakinan dan mental positif yang mana keduanya memiliki pengaruh terhadap sikap percaya diri individu, dan unsur positif ini dapat terbangun dengan kokoh serta dapat memberikan pengaruh terhadap perilaku setelah diyakinkan (Othman, 2019). Lebih jauh, Irwan Wiseful menyebutkan dalam bukunya yang berjudul Action Power bahwa pikiran seseorang menentukan alur kehidupan yang dihadapinya (Berutu, 2013). Berpikir positif merupakan cara untuk memperbaiki berbagai aspek kehidupan manusia (Mousavi et al., 2015).

Mayrawati menyatakan bahwa pikiran memiliki pengaruh besar terhadap semua perilaku yang dinampakkan (Mayrawati, 2019), karena pikiran merupakan pelopor dari segalanya, maka jika pikiran mengarah kepada hal negatif, maka perilaku yang dimunculkan memiliki kemungkinan besar juga akan negatif (Faiz et al., 2019), sehingga kemudian akan memberikan kesan negatif pada kehidupan. Sebagaimana penelitian yang dilakukan oleh Sabati, dikemukakan bahwa semakin tinggi tingkatan berpikir positif seseorang maka semakin rendah kecemasan yang dialami dalam hal berkomunikasi, dan lain-lain (Sabati, 2017). Sebaliknya semakin rendah tingkat berpikir positif seseorang maka semakin tinggi kecemasan.

Salah satu bentuk intervensi yang dapat digunakan untuk menangani stage fright adalah hipnosis. Hipnosis dapat mengeksplorasi keterbatasan individu, membebaskan potensi bawah sadar untuk dapat mengatasi sebuah masalah (Zeig, 1980). Sebagai sebuah aplikasi yang mendukung kepentingan berjalannya terapi, hipnosis merupakan sebuah metode yang dapat mengintervensi dengan baik terhadap peningkatan motivasi belajar dan penurunan stress belajar yang dialami oleh seorang individu, selain itu hipnosis juga dapat membantu memperbaiki kebiasaan buruk serta memperkuat memori (Bradford, 1963). Neill dan Steve mengatakan bahwa terapi yang dibantu dengan hipnosis juga dapat membantu individu untuk menerima pikiran positif degan menjauhkan pikiran negatif (Hasibuan \& Mendrofa, 2019). Paparan beberapa hasil penelitian menunjukkan hipnoterapi berpengaruh terhadap penurunan tingkat kecemasan (DS et al., 2014) dan meningkatkan motivasi belajar mahasiswa (Hasibuan \& Mendrofa, 2019).

Keunggulan hipnosis dari metode lain yang dapat digunakan dalam terapi adalah bahwa hipnosis hanya menggunakan kekuatan sugesti untuk memandu pikiran (Jayanti, 2019), dengan mengubah gelombang otak agar klien masuk kedalam kondisi yang sangat santai dan menjadi jauh lebih nyaman, sehingga hipnoterapi menjadi metode yang efektif dalam mengatasi permasalahan kognitif dan perilaku (Niraski, 2015). Hasibuan dan Mendrofa mengemukakan bahwa dengan metode hipnosis, mahasiswa akan terbantu dalam membangkitkan semangat belajar dan dapat memasukkan sugesti positif ke dalam pikiran mereka dengan tujuan meningkatkan rasa percaya diri, motivasi, dan citra diri yang positif (Hasibuan \& Mendrofa, 2019). Dengan demikian, metode hipnosis merupakan metode yang tepat untuk memberikan intervensi kepada individu yang mengalami stress ringan yang dalam penelitian ini difokuskan kepada salah satu bentuk stress ringan yang umum dialami oleh mahasiswa baru, yaitu stage fright. Hal ini dikuatkan dengan penelitian yang dilakukan oleh Hendriyanto, Sriati dan Fitria yang 
mengungkapkan bahwa hipnoterapi dapat mengurangi tingkat stres pada mahasiswa (Hendriyanto et al., 2012).

Bentuk intervensi lain untuk menangani stress ringan seperti stage fright selain hypnosis adalah Neuro Linguistic Programming (NLP). Penelitian yang dilakukan oleh Pummy Sheoran dengan subjek wanita berusia 24 tahun yang menderita depresi dan kecemasan menunjukkan bahwa tehnik NLP efektif dalam mengobati kecemasan, depresi dan stress (Sheoran, 2016). Hasil penelitian yang dilakukan oleh Albalawi juga menunjukan teknik-teknik dalam NLP efektif dalam meningkatkan kualitas hidup mahasiswa (Albalawi, 2014) dan strategi penggunaan pelatihan NLP berpengaruh terhadap tingkat kecemasan, dalam artian menurunkan kecemasan tersebut (Abdivarmazan \& Sylabkhori, 2016).

NLP dapat membantu seseorang dalam berkomunikasi dengan dirinya sendiri secara lebih baik, mengurangi ketakutan tanpa alasan, serta mengontrol emosi negatif dan kecemasan. (Dryden \& Vos, 1999). Dengan demikian NLP sangat relevan untuk dijadikan salah satu teknik terapi dalam penelitian ini, yaitu untuk menjadikan subjek menjadi seorang yang lebih berkualitas daripada dirinya yang sekarang dan meminimalisir rasa cemas yang ia alami ketika akan show up. Dalam penelitian ini, peneliti menawarkan pengembangan teknik NLP yang dikombinasikan dengan teknik hipnosis untuk menanamkan anchor yang diberinama "panggung positif" untuk mengatasi stage fright.

Penelitian dengan model pengembangan diukur kualitas hasil penelitiannya melalui kemanfaatan produk yang telah teruji validitasnya (Sugiyono, 2019), maka dari itu perlu dilakukan uji validasi dengan melibatkan para ahli yang berhubungan dengan produk penelitian yang sedang dikembangkan, hal ini dimaksudkan untuk mengetahui apakah produk penelitian yang dikembangkan siap untuk dilakukan uji lapangan (Borg \& Gall, 1989). Dengan demikian, penelitian ini bertujuan untuk menguji coba modul panduan yang khusus dibuat untuk menanamkan "panggung positif" kepada mahasiswa baru UIN Sunan Kalijaga dengan tujuan agar subjek mampu untuk menghadapi situasi yang tidak nyaman atau memberi tekanan sehingga menyebabkan munculnya stage firight. Hal ini dilakukan melalui sebuah pelatihan dengan menggunakan sebuah modul panduan terapi Hipno-NLP

\section{METODE PENELITIAN}

\section{Rancangan Penelitian}

Penelitian ini merupakan proses penelitian dan pengembangan (R\&D) level 3, yaitu meneliti dan mengembangkan produk yang sudah ada (Sugiono, 2019). Dalam penelitian ini, peneliti berfokus pada fenomena stage fright dan mengembangkan modul Hypnotherapy serta modul Neuro Linguistic Programming (NLP) yang kemudian digabungkan dalam sebuah panduan pelatihan Hipno-NLP yang bertujuan untuk mengatasi stage fright. Dalam proses penelitian, peneliti menggunakan pola komunikasi NLP sebagai dasar utama dalam menyampaikan materi kepada klien.

Gambar 1 menunjukkan bahwa komunikasi yang terjadi pada manusia diawali oleh sebuah kejadian yang dialami seseorang (external event). Kejadian tersebut merupakan informasi yang memasuki pikiran melalui modalitas, yaitu visual, kinestetik, auditori, olfaktori, dan gustatori (Gunawan, 2011). Informasi tersebut kemudian menjadi sebuah pengalaman. Sebelum menjadi pengalaman yang menetap (internal representation), pikiran menyeleksi pengalaman tersebut melalui tiga cara, yaitu deletion (penghapusan), distorsi (menghubungkan antara berbagai kejadian), dan generalisasi (penyamarataan) (Rambe \& Yarni, 2019). Dalam hal ini, spiritual education akan menjadi external event 
yang disampaikan oleh pemateri kepada klien dengan menyisipkan teknik pacing and leading dalam menyampaikan materi tersebut. Hipnoterapi difungsikan untuk membuka filter yang secara alami berfungsi dalam kognisi individu untuk membatasi informasi yang masuk ke dalam pikiran individu dengan tujuan untuk menjadikannya internal representation bagi klien. Teknik yang akan digunakan adalah teknik relaksasi. Teknik ini dipilih dengan pertimbangan bahwa tidak semua klien memiliki tingkat sugestifitas yang tinggi. Proses pembukaan filter berfungsi untuk menanamkan lebih dalam materi yang telah disampaikan sebelumnya, dan menanamkan stacking anchor yang bersifat kinestetik kepada klien untuk memanggil kembali keyakinan yang telah tertanam ketika dibutuhkan. Dalam menerapkan metode yang telah dijelaskan, peneliti menyusun sebuah panduan yang akan digunakan dalam proses penelitian, yang telah digambrkan pada gambar 2.

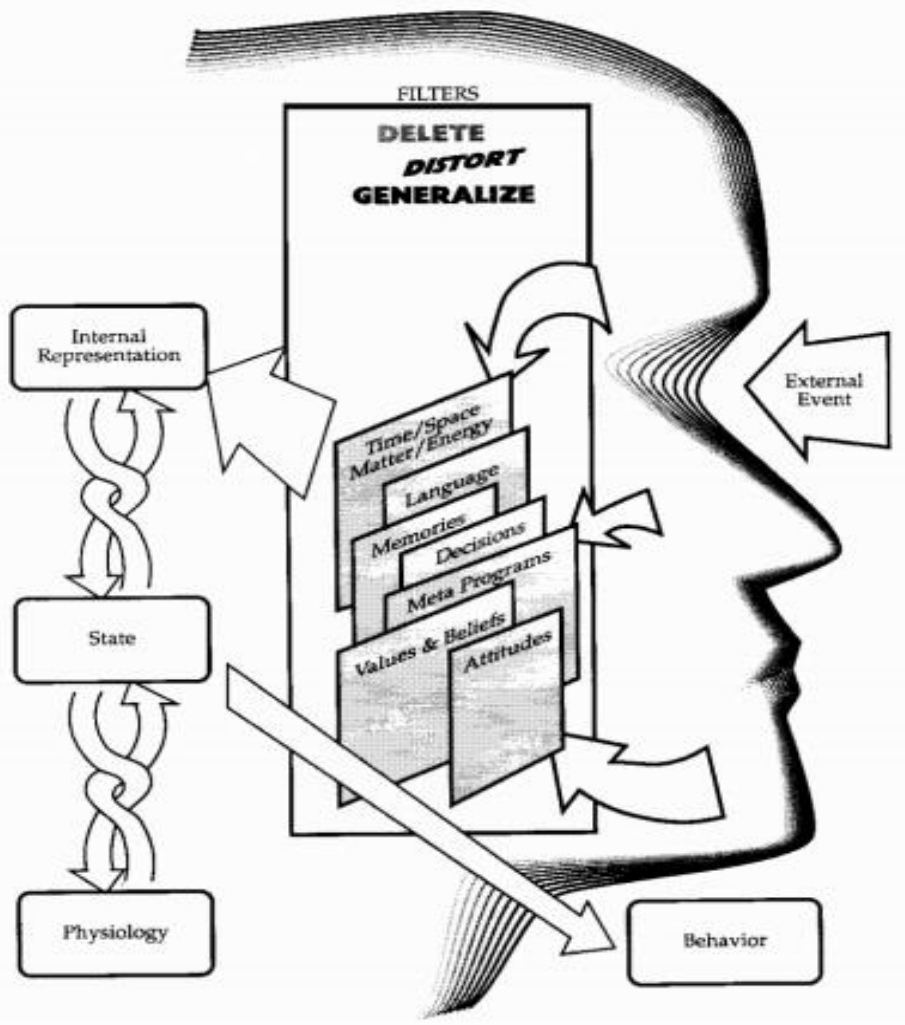

Gambar 1. Model Komunikasi NLP (Wikanengsih, 2012).

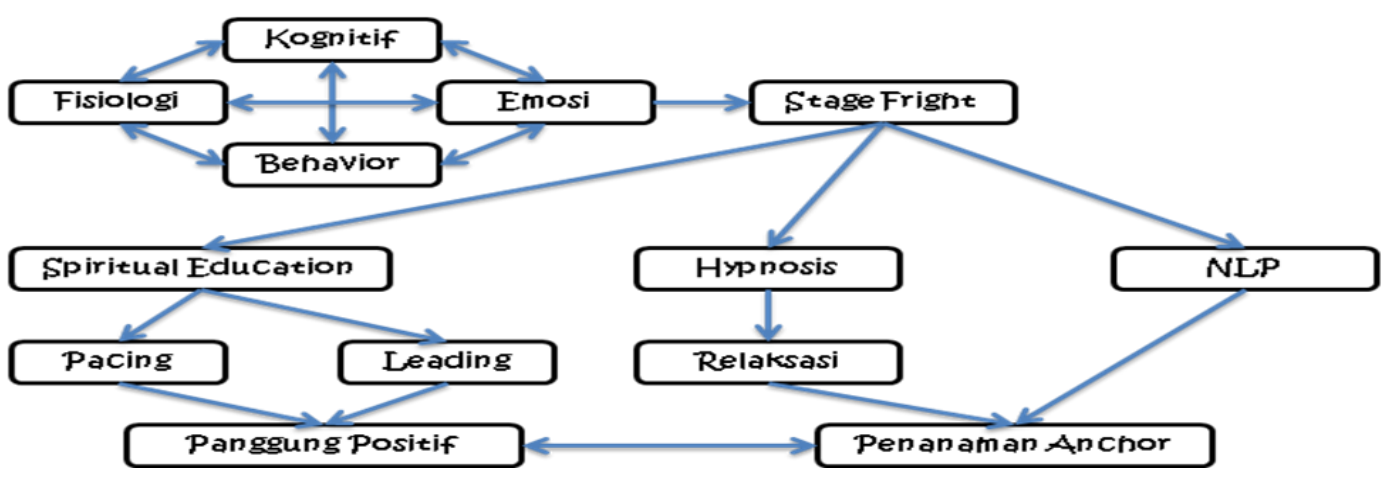

Gambar 2. Modul Panduan. 


\section{Sumber Data}

Subjek dipilih oleh peneliti menggunakan teknik porpusive sampling atau berdasarkan karakter tertentu yang dimiliki oleh sampel, yaitu merupakan mahasiswa baru UIN Sunan Kalijaga yang memiliki indikasi mengalami stage fright. Berdasarkan hasil dari angket yang disebar kepada mahasiswa baru UIN Sunan Kalijaga, terdapat 48 mahasiswa baru UIN Sunan Kalijaga yang mengalami stage fright yang kemudian diambil $37 \%$ dari jumlah tersebut untuk dijadikan sampel penelitian, yakni sebanyak 18 mahasiswa.

\section{Teknik Pengumpulan Data}

Pengumpulan data dalam penelitian ini menggunakan instrument angket. Angket yang disebarkan berupa alat ukur intensitas indikator stage fright yang muncul pada subjek dengan menggunakan skala likert (Sangat setuju, Setuju, Tidak Setuju, Sangat Tidak Setuju) yang telah melalui uji realibilitas dengan $\mathrm{R}$ hitung $>\mathrm{R}$ tabel $=$ valid, $\mathrm{R}$ hitung $<\mathrm{R}$ tabel $=$ tidak valid. $\mathrm{R}$ tabel $=\mathrm{N}=34$ distribusi nilai $5 \%=0.227$. Alat ukur tersebut bertujuan untuk mengetahui intesnitas, atau seberapa besar kemungkinan subjek memiliki stage fright berdasarkan indikator stress ringan yang disebutkan oleh Nazila dan Yuliana (2019) dibagi dalam tiga aspek yaitu: 1) Indikator psikologis yang meliputi: mudah tersinggung, kurang komunikatif, sering melamun dan lelah secara mental. 2) Indikator pada fisik yang meliputi: meningkatnya detak jantung dan tekanan darah, mudah lelah secara fisik, sering merasa pusing kepala dan memiliki masalah pada tidur. 3) Indikator pada perilaku yang meliputi: merokok berlebihan (jika perokok), menunda atau menghindar dari tugas atau rutinitas yang harus dilakukan, perilaku maladaptif dan perilaku makan yang tidak normal (Nazila \& Yuliana, 2019).

\section{Teknik Analisis Data}

Jenis data yang digunakan dalam proses penelitian merupakan data kualitatif. Data kualitatif tersebut berupa pernyataan-pernyataan dari subjek penelitian yang didapatkan dari wawancara terstruktur via whatsapp. Uji ahli dilakukan dalam dua bagian, yaitu uji materi dan uji aplikasi. Proses uji coba dilakukan dalam empat tahap dan dibagi berdasarkan materi yang ditulis dalam modul. Adapun subjek penguji dalam penelitian ini disampaikan pada tabel 1 .

Tabel 1. Daftar Penguji Ahli

\begin{tabular}{ccc}
\hline Nama & Ahli & Institusi \\
\hline Hafisa Idayu & Materi & UIN Sunan Kalijaga \\
\hline Ahmad Rifai Sinaga & Aplikasi & UIN Sunan Ampel \\
\hline Norma Majid & Materi dan Aplikasi & UPI \\
\hline
\end{tabular}

Uji coba produk dilakukan dua kali dalam setiap tahap uji coba, yaitu kepada satu individu, kemudian kepada sekelompok individu. Analisis data dilakukan untuk melihat nilai stage fright pada individu. Peneliti menggunakan teknik display data kualitatif yang telah diperoleh dari lapangan dengan dibantu oleh penguji ahli sehingga kemudian dapat diambil kesimpulan

\section{HASIL DAN PEMBAHASAN}

\section{Hasil Penelitian}

Uji aplikasi modul panduan dilakukan kepada 18 subjek uji coba yang terdiri dari 1 individu pada uji lapangan terbatas tahap pertama, 9 individu pada uji lapangan terbatas 
tahap kedua, 1 individu pada uji lapangan utama tahap pertama, 5 individu pada uji lapangan utama tahap kedua, 1 individu pada uji lapangan operasional tahap pertama dan 1 individu pada uji lapangan operasional tahap kedua.

Pada tahap desain, ditemukan bahwa langkah-langkah yang dilakukan dalam menentukan konsep Hipno-NLP untuk menangani stage fright adalah sebagai berikut: 1) memilih materi yang disampaikan dalam spiritual education 2) menghubungkan dengan stage fright 3) memilih teknik yang dilakukan dalam hipnoterapi 4) membuat bentuk anchor 5) menyusun kerangka modul 6) melakukan uji coba.

Adapun langkah-langkah yang dilakukan dalam proses pengembangan akan dipaparkan sebagai berikut: 1) mengumpulkan materi mengenai berpikir positif menurut perspektif agama 2) mengumpulkan materi mengenai berpikir positif menurut persfektif psikologi 3) merumuskan konsep panggung positif 4) menggabungkan ketiga materi dalam satu bentuk edukasi 5) membuat konsep penyampaian materi 6) memilih teknik yang dilakukan dalam hipnoterapi 7) merumuskan verbalisasi yang digunakan dalam relaksasi 8) membentuk anchor 9) merumuskan verbalisasi yang digunakan dalam penanaman anchor 10) merumuskan verbalisasi untuk memperdalam anchor 11) merumuskan verbalisasi untuk membawa klien kembali ke alam sadar.

Penilaian tahap pertama merupakan pengujian internal terhadap rancangan produk (Gall et al., 2003), diserahkan sepenuhnya kepada ahli. Uji coba dilakukan beberapa kali hingga akhirnya ditemukan desain rancangan modul yang dianggap paling baik dan relevan dengan kebutuhan klien.

Hasil uji pertama dan seterusnya yang oleh Borg dan Gall (2003) disebut dengan tahap kedua (uji lapangan terbatas), ketiga (uji lapangan utama), dan keempat (uji lapangan operasional) akan dipaparkan mengikuti tahap uji coba yang telah dilakukan.

Tabel 2. Tahap Uji Coba

\begin{tabular}{|c|c|c|}
\hline Tahap & Materi & Hasil Uji \\
\hline \multirow{4}{*}{ Pertama } & $\begin{array}{l}\text { Materi I: Ranah spesifik terapi } \\
\text { dan definisi teknik }\end{array}$ & \multirow{4}{*}{$\begin{array}{l}\text { Telah mendapatkan persetujuan dari } \\
\text { ahli dan telah disosialisasikan kepada } \\
\text { terapis yang bertugas }\end{array}$} \\
\hline & $\begin{array}{l}\text { Materi II: Edukasi, pacing and } \\
\text { leading dan panggung positif }\end{array}$ & \\
\hline & $\begin{array}{l}\text { Materi III: Hipnoterapi dan } \\
\text { relaksasi }\end{array}$ & \\
\hline & $\begin{array}{l}\text { Materi IV: Anchor, Circle of } \\
\text { The Possitive Stage }\end{array}$ & \\
\hline \multirow{6}{*}{ Kedua } & \multirow{3}{*}{$\begin{array}{l}\text { Materi II: Edukasi, pacing and } \\
\text { leading dan panggung positif }\end{array}$} & Tahap I \\
\hline & & $\begin{array}{l}\text { Diujikan kepada satu individu dan hasil } \\
\text { yang didapatkan adalah sebagai berikut: } \\
\text { "kalo untuk presentasi belum sy coba } \\
\text { kak, belum ada tugas presentasi lagi, } \\
\text { tapi saya berani nanya..." }\end{array}$ \\
\hline & & Tahap II \\
\hline & \multirow{3}{*}{$\begin{array}{l}\text { Materi II: Edukasi, pacing and } \\
\text { leading dan panggung positif }\end{array}$} & $\begin{array}{l}\text { Diujikan kepada } 9 \text { sampel random dan } \\
\text { mendapatkan hasil sebagai berikut: }\end{array}$ \\
\hline & & Sampel 1 "lumayan kak...” \\
\hline & & Sampel 2 "practicable banget..." \\
\hline
\end{tabular}




\begin{tabular}{|c|c|c|}
\hline \multicolumn{3}{|c|}{ Lanjutan ... } \\
\hline Kedua & & $\begin{array}{l}\text { Sampel } 3 \text { "aku masih nyoba-nyoba kak" } \\
\text { Sampel } 4 \text { "aku gak tau ini termasuk } \\
\text { kemajuan ato enggak, rasanya jadi lebih } \\
\text { berani aja gitu, soalnya kita yang } \\
\text { ngatur..." "aslinya aku ga demam } \\
\text { Sampel } 5 \text { "asin kemarin pas aku jadi } \\
\text { panggung sih, tapi kemaring } \\
\text { moderator, lebih santai jadinya..." } \\
\text { Sampel } 6 \text { "aku belum ngerasain } \\
\text { bedanya..." } \\
\text { Sampel } 7 \text { "gak tau kak, aku gak bisa } \\
\text { bedain..." "kok biasa aja ya?" } \\
\text { Sampel } 8 \text { "kok } \\
\text { Sampel } 9 \text { "belum tau bedanya..." }\end{array}$ \\
\hline \multirow{2}{*}{ Ketiga } & $\begin{array}{l}\text { Materi III: Hipnoterapi dan } \\
\text { relaksasi }\end{array}$ & $\begin{array}{l}\text { Tahap I } \\
\text { Diujikan kepada satu individu dan } \\
\text { berhasil mencapai alam bawah sadar } \\
\text { klien }\end{array}$ \\
\hline & $\begin{array}{l}\text { Materi III: Hipnoterapi dan } \\
\text { relaksasi }\end{array}$ & $\begin{array}{l}\text { Tahap II } \\
\text { Diujikan kepada } 5 \text { sampel random dan } \\
\text { semuanya berhasil masuk hipnosis } \\
\text { bawah sadar. }\end{array}$ \\
\hline \multirow{4}{*}{ Keempat } & $\begin{array}{l}\text { Materi IV: Anchor, Circle of } \\
\text { The Possitive Stage }\end{array}$ & $\begin{array}{l}\text { Tahap I } \\
\text { Diuji kepada satu individu tanpa } \\
\text { relaksasi. Uji coba ini dilakukan dengan } \\
\text { praktik langsung. Klien diminta } \\
\text { membayangkan sebuah lingkaran yang } \\
\text { berisi semua state yang ia butuhkan, dan } \\
\text { berjalan ke dalamnya. Hasil yang } \\
\text { didapatkan adalah sebagai berikut: } \\
\text { "ringan kak, serius!" }\end{array}$ \\
\hline & & $\begin{array}{l}\text { Tahap II } \\
\text { Diuji kepada satu individu dengan } \\
\text { relaksasi. }\end{array}$ \\
\hline & $\begin{array}{l}\text { Materi IV: Anchor, Circle of } \\
\text { The Possitive Stage }\end{array}$ & $\begin{array}{l}\text { Konsep yang dilakukan pada dasarnya } \\
\text { sama dengan uji coba tanpa relaksasi, } \\
\text { hanya saja dalam hal ini klien masuk ke } \\
\text { dalam circle of The Possitive Stage } \\
\text { dalam alam bawah sadarnya. Adapun } \\
\text { hasil yang didapatkan adalah sebagai } \\
\text { berikut: } \\
\text { "aku beneran ngerasain bedanya, kayak } \\
\text { gaada beban, kita yang ngatur } \\
\text { semuanya. Aku jadi orang yang sesuai } \\
\text { mauku, sesuai mauku pokoknya..." }\end{array}$ \\
\hline & $\begin{array}{l}\text { Materi IV: Anchor, Circle of } \\
\text { The Possitive Stage }\end{array}$ & $\begin{array}{l}\text { Tahap III } \\
\text { Belum terlaksana }\end{array}$ \\
\hline
\end{tabular}


Lanjutan...

$\begin{array}{lll}\text { Keempat } & \begin{array}{l}\text { Materi IV: Anchor, Circle of } \\ \text { The Possitive Stage }\end{array} & \begin{array}{l}\text { Tahap III } \\ \text { Belum terlaksana }\end{array}\end{array}$

Evaluasi untuk produk yang dikembangkan adalah bahwa metode hipnosis dengan teknik relaksasi yang digunakan untuk memasuki alam bawah sadar terlalu panjang untuk orang yang memiliki tingkat sugestifitas yang tinggi. Namun hal ini tidak dapat diusahakan lagi oleh peneliti mengingat tidak semua klien memiliki tingkat sugestifitas yang sama.

\section{Pembahasan}

Proses uji coba dalam penelitian ini dilakukan dalam empat tahap. Pada tahap pertama rancangan produk diuji berdasarkan pendapat para ahli terhadap rancangan produk tersebut (Sugiono, 2019). Nugraha dkk. menyebutkan bahwa tahap awal merupakan pendefinisian kebutuhan klien akan sebuah intervensi, kemudian dirancang sebuah bentuk terapi Hipno-NLP berdasarkan hasil analisan definisi tersebut (Nugraha et al., n.d.). Selanjutnya rancangan telah disetujui sebagai produk yang relevan dengan kebutuhan klien setelah melewati beberapa kali refisi yang disesuaikan dengan koreksi penguji ahli. Rancangan modul hipno-NLP yang telah melewati uji coba tahap pertama berisi pemaparan singkat mengenai definisi dari teknik-teknik yang akan digunakan, edukasi mengenai ilusi positif, kemudian tentang hipnosis dan relasksasi serta bentuk anchor yang akan digunakan. Hal ini ditujuakan agar setiap terapis yang menggunakan modul memiliki gambaran tentang proses terapi yang dilakukan dan lebih memahami outcome dari terapi tersebut sehingga diperoleh proses intervensi yang sesuai dengan tujuan utama pembuatan modul.

Sebagian dari pengembangan modul membahas mengenai pola berfikir positif dalam perfektif Islam. Islam memandang bahwa seseorang yang memiliki mental yang sehat akan menunjukkan perilaku, pikiran dan perasaan yang mencerminkan ajaran Islam (Ramayulis, 2016), di mana seluruh muslim dituntut untuk senantiasa berpikir baik/positif (husnuzhan) dan menghindari berpikir negatif (Ilmy, 2008) sehingga dapat memenuhi indikator sebagai hamba yang taat. Modul Pengembangan Hipno-NLP bertujuan untuk meringankan gangguan stress ringan dengan satu bentuk tertentu demi tercapainya sebuah keadaan mental yang sehat. Ramayulis menyebutkan bahwa pada dasarnya mental yang sehat ditandai dengan terhindarnya individu dari neurosis (Ramayulis, 2016). Hal ini menunjukkan bahwa pikiran yang positif merupakan salah satu gambaran dari mental yang sehat. Untuk mengakomodasi hal tersebut, materi II dalam penelitian ini berisi edukasi keagamaan mengenai berpikir positif (husnuzhan) dan pandangan psikologi mengenai hal tersebut serta cara penyampaiannya dengan menyisipkan teknik pacing and leading yang akan memunculkan output berupa "panggung positif", yaitu sebuah keadaan dimana klien seolah-olah merupakan sutradara atas sebuah keadaan yang akan ia hadapi, dan klien tersebut merancang skenario yang akan dimainkan oleh orang-orang yang terlibat dalam keadaan tersebut. Adapun teknik Pacing and leading bertujuan untuk membentuk yes-set conditioning, di mana peneliti mengondisikan klien secara sadar maupun tidak sadar menyetujui informasi yang diberikan oleh peneliti (Putra, 2016).

Palmer menyebutkan bahwa pada dasarnya setiap individu memiliki perlengkapan yang sama untuk memproses dunia, namun cara setiap orang menyimpulkan apa yang didapat dari proses tersebut berbeda (Palmer, 2011). Husnuzhan yang dalam hal ini disebut dengan berpikir positif merupakan salah satu cara untuk memperoleh kesimpulan dari proses tersebut. Selain itu Nurmaliyah menyebutkan bahwa berpikir positif merupakan indikator yang dibutuhkan untuk menurunkan tingkat stress (Nurmaliyah, 
2013), yang dalam penelitian ini berbentuk stage fight dalam proses pembelajaran di kelas atau di luar kelas. Hal ini selaras dengan pernyataan Andinny yang menyatakan bahwa berpikir positif dapat memberikan pengaruh pada proses belajar (Andinny, 2013) dan menurunkan tingkat kecemasan pada mahasiswa (Adriansyah et al., 2015) yang merupakan salah satu indikator awal munculnya stage fright. Selanjutnya hipnoterapi dan teknik relaksasi digunakan untuk internalisasi external event, yaitu anchor yang digunakan dalam intervensi.

Agustin dkk. menyatakan bahwa hipnoterapi dan terapi relaksasi merupakan alternatif yang dapat digunakan untuk menurunkan tingkat kecemasan (Agustin et al., 2020). Hal ini didukung dengan pernyataan Soh (2015) yang secara spesifik menyebutkan bahwa hipnoterapi dapat digunakan untuk mengatasi demam panggung, yang dalam penelitian ini disebut stage fright (Soh, 2015). Pada prosesnya, hipnoterapi menggunakan teknik relaksasi untuk menanamkana anchor pada diri klien setelah klein sudah berhasil di arahkan kepada pikiran positif dengan menggunakan teknik pacing and leading. Adapun bentuk anchor yang ditanamkan kepada klien adalah stacking anchor yaitu mengumpulkan kualitas state pada lokasi yang sama (Putra, 2016). Dalam hal ini peneliti menggunakan circle of the positive stage sebagai tempat untuk mengumpulkan skenario terbaik klien dalam menghadapi keadaan yang memicu munculnya stage fright. Palmer menyebutkan bahwa Stacking anchor dan teknik NLP lainnya merupakan sebuah terapi dengan efektifitas berjangka pendek (Palmer, 2011), karena itu peneliti menanamkan sebuah gerakan fisiologis sebagai kode untuk "memanggil kembali" circle of the positive stage tersebut ketika dibutuhkan, misalnya dengan menggenggam tangan, menepuk dada dan lain-lain. Klien diminta untuk menentukan sendiri gerakan atau hal lain yang menurutnya paling nyaman.

Proses uji coba dilakukan dengan mengikuti alur cerita yang disampaikan oleh klien dan mendukung semua pernyataan klien, kemudian mengarahkannya kepada hal yang menjadi tujuan utama terapi. Hal ini selaras dengan pernyataan Saleh dan Warsito (2019) bahwa tujuan teknik pacing and leading adalah untuk menyamakan posisi dengan klien (pacing) kemudian menetralisasi percakapan dengan pertanyaan yang mengarahkan kepada jawaban yang diinginkan peneliti (leading) (Saleh \& Warsito, 2019). Triana dan Yanti menyatakan bahwa teknik ini dapat digunakan untuk meningkatkan keterampilan komunikasi yang efektif (Triana \& Yanti, 2018). Komunikasi efektif dibutuhkan pada proses terapi agar pada tahap selanjutnya peneliti dapat mengarahkan percakapan kepada pikiran positif dalam dua persfektif, yaitu agama dan psikologi sebelum mulai untuk menyampaikan konsep 'panggung positif' kepada klien.

Latipun menyatakan bahwa pada dasarnya klien membutuhkan dukungan dari konselor dan klien memiliki persepsi sendiri dalam melihat pengalaman-pengalamannya (Latipun, 2017). Dalam proses konseling, tahap awal yang harus dilakukan oleh seorang konselor adalah membangun rapport agar tercipta iklim yang memungkinkan klien dapat berkembang (Latipun, 2017), hal ini dapat dilakukan dengan menciptakan pola komunikasi yang nyaman bagi klien, baik komunikasi verbal, komunikasi vokal dan komunikasi tubuh (Nelson-Jones, 2012). Setelah tercipta iklim yang nyaman, konselor dapat menlajutkan ke tahap terapi berikutnya

Pada teknik pacing and leading, dalam proses pacing terapis selalu mendukung pernyataan yang dikeluarkan oleh klien, lalu pada porsi tertentu, mengarahkan klien kepada hal yang ingin disampaikan pada proses konseling. Adapun Porsi Pacing and leading yang diberikan kepada klien ditampilkan pada gambar 3. 


\begin{tabular}{|c|c|c|c|c|}
\hline $\mathbf{P}$ & $\mathbf{P}$ & $\mathbf{P}$ & $\mathbf{P}$ & $\mathbf{P}$ \\
\hline $\mathbf{P}$ & $\mathbf{P}$ & $\mathbf{P}$ & $\mathbf{P}$ & $\mathbf{L}$ \\
\hline $\mathbf{P}$ & $\mathbf{P}$ & $\mathbf{P}$ & $\mathbf{L}$ & $\mathbf{L}$ \\
\hline $\mathbf{P}$ & $\mathbf{P}$ & $\mathbf{L}$ & $\mathbf{L}$ & $\mathbf{L}$ \\
\hline $\mathbf{P}$ & $\mathbf{L}$ & $\mathbf{L}$ & $\mathbf{L}$ & $\mathbf{L}$ \\
\hline $\mathbf{L}$ & $\mathbf{L}$ & $\mathbf{L}$ & $\mathbf{L}$ & $\mathbf{L}$ \\
\hline
\end{tabular}

Gambar 3. Porsi pacing and leading (Putra, 2016)

Gambar 3 menunjukkan bahwa hal pertama yang harus dilakukan dalam teknik ini adalah pacing, yaitu mendukung semua pernyataan klien, yang kemudian porsi dukungan tersebut semakin berkurang dan digantikan oleh arahan kepada hal tertentu yang menjadi tujuan terapi. Hal tersebut juga dinyatakan secara spesifik oleh Rahman (2010) bahwa pacing dan leading dapat menyelaraskan diri konselor dengan kondisi klien dan meningkatkan sensitifitas agar kemudian mampu untuk lebih memahami keadaan klien sehingga dapat mempengaruhi pikiran klien untuk melaksanakan tujuan intervensi (Rahman, 2010).

\section{SIMPULAN}

Berdasarkan ujicoba yang dilakukan, kesimpulan yang didapatkan adalah bahwa terdapat pengaruh positif pada subjek uji setelah diterapkan intervensi yang disiapkan dalam modul. Dari penelitian ini diketahui bahwa stage fright pada dasarnya merupakan sebuah akibat dari persepsi negatif terhadap diri sendiri yang kemudian muncul dengan bentuk perilaku maladaptif dan dapat diperparah oleh rasa takut dan cemas. Penelitian ini perlu untuk dilanjutkan dan diharapkan dapat menjadi alternatif yang dapat dilakukan oleh setiap orang yang mengalami kesulitan yang sama dengan subjek dalam penelitian ini.

\section{UCAPAN TERIMAKASIH}

Ucapan terimakasih disampaikan pada program Pascasarjana Universitas Islam Negeri Sunan Kalijaga Yogyakarta yang telah memfasilitasi terlaksanannya penelitian ini. Ucapan terimakasih juga disampaikan kepada Dr. Casmini, S. Ag, MSi, yang telah membimbing dalam proses pelaksanaan penelitian ini.

\section{DAFTAR PUSTAKA}

Abdivarmazan, M., \& Sylabkhori, Z. (2016). Effectiveness of training of NeuroLinguistic Programming (NLP) strategies on reducing social anxiety. World Scientific News, 60, 67-77.

Adriansyah, M. A., Diah, R., \& Netty, D. P. (2015). Pengaruh Terapi Berpikir Positif dan Cognitive Behavior Therapy (CBT) Terhadap Penurunan Kecemasan Pada Mahasiswa Universitas Mulawarman. Jurnal Psikostudia Universitas Mulawarman, 4(2), 105-125.

Agustin, R. R., Koeryaman, M. T., \& DA, I. A. (2020). Gambaran Tingkat Cemas, Mobilisasi, dan Nyeri pada Ibu Post Operasi Sectio Sesarea di RSUD dr. Slamet 
Garut. Jurnal Kesehatan Bakti Tunas Husada: Jurnal Ilmu Ilmu Keperawatan, Analis Kesehatan Dan Farmasi, 20(2), 223-234.

Albalawi, K. S. (2014). Effectiveness of Neuro-Linguistic Programming on Enhancing Univerity Student' Quality of Life. Journal of Arts \& Sciences, 7(6), 431-442.

Andinny, Y. (2013). Pengaruh Konsep Diri dan Berpikir Positif terhadap Prestasi Belajar Matematika Siswa. Formatif: Jurnal Ilmiah Pendidikan MIPA, 3(2), 126-135.

Berutu, I. W. (2013). Action Power. PT Alex Media Komputindo.

Borg, W. R., \& Gall, M. D. (1989). Educational Research: An Introduction (5th ed.). Longman.

Bradford, C. (1963). How to hypnotize. Stravon Publisher.

Dryden, G., \& Vos, J. (1999). The Learning Revolution: To Change The Way The World Learns. Torrance, CA: The Learning Web.

DS, A. I., Kristiawati, S. P., \& Supriadi. (2014). Pengaruh Hipnoterapi Terhadap Penurunan Tingkat Kecemasan pada Pasien yang Menjalani Kemoterapi di RS Telogorejo Semarang. Jurnal Ilmu Perawatan dan Kebidanan, 1-10.

Faiz, A., Yandri, H., Kadafi, A., Mulyani, R. R., \& Nofrita. (2019). Pendekatan Tazkiyatun An-Nafs untuk membantu mengurangi emosi negatif klien. Counsellia: Jurnal Bimbingan Konseling, 9(1), 65-78.

Gall, M. D., Gall, J. P., \& Borg, W. R. (2003). Educational Research: An Introduction. Longman.

Gunawan, A. W. (2011). Born To Be Genius. PT Gramedia Pustaka Utama.

Hasibuan, M. T. D., \& Mendrofa, H. K. (2019). Pengaruh Hipnoterapi Terhadap Stres Belajar dalam Meningkatkan Motivasi Belajar Mahasiswa di Sekolah Tinggi Ilmu Kesehatan Kota Medan. Jurnal Keperawatan Dan Fisioterapi, 2(1), 42-46.

Hendriyanto, B., Sriati, A., \& Fitria, N. (2012). Pengaruh Hipnoterapi Terhadap Tingkat Stres Mahasiswa Fakultas Ilmu Keperawatan Universitas Padjadjaran Angkatan 2011. Students E-Journal, 1(1).

Ilmy, B. (2008). Pendidikan Agama Islam. Penerbit Grafindo Media Pratama.

Jayanti, A. F. (2019). Perbedaan Keikutsertaan Hypnobirthing dengan Tingkat Kecemasan Ibu Hamil dalam Menghadapi Persalinan di Kabupaten Sidoarjo. Jurnal Keperawatan Muhammadiyah, 91-98.

Latipun. (2017). Psikologi Konseling. UMM Press.

Mambu, J. Y., Wahyudi, A., \& Posumah, F. (2019). Aplikasi Simulasi Public Speaking Berbasis Virtual Reality. Cogito Smart Journal, 4(2), 327-336.

Mayrawati, A. C. C. (2019). Peran Relawan Sosial dalam Pengembangan Karakter Anak di Surabaya Children Crisis Center. J+Plus UNESA, 8(1).

Mousavi, E., Esmaeili, A., \& Saless, S. S. (2015). The Effect of Positive Thinking on Quality of Live and Resiliency of Cancer Patient. Rzavi International Medicine, $3(3), 24-28$.

Nazila, \& Yuliana. (2019). Pengaruh Beban Kerja Dan Stress Kerja Terhadap Kinerja Pegawai Badan Pengawasan Keuangan Dan Pembangunan Perwakilan Provinsi Aceh. SEMDI UNAYA, 273-282.

Nelson-Jones, R. (2012). Pengantar Keterampilan Konseling. Pustaka Pelajar.

Niraski, V. (2015). Pengaruh Hipnoterapi Terhadap Tingkat Nyeri Pada Ibu Post Sectio Caesarea Di Rsb Jeumpa Pontianak Tahun 2015. Jurnal Proners, 3(1), 1-11.

Nugraha, A. B., Ramalis, T. R., \& Purwanto. (n.d.). Pengembangan Bahan Ajar Web Fisika SMP Berorientasi Literasi Sains pada Materi Kalor. Jurnal Wahana Pendidikan Fisika, 2(1), 11-14.

Nurmaliyah, F. (2013). Menurunkan stres akademik siswa dengan menggunakan teknik self instruction / Faridah Nurmaliyah [Thesis]. Universitas Negeri Malang. 
Othman, A. S. (2019). Terapi Negative Thinking Dalam Meningkatkan Percaya Diri Pada Seorang Guru Sekolah Menengah Kebangsaan Tinjar Baram Miri Sarawak. Undergraduate, Universitas Islam Negeri Sunan Ampel Surabaya Indonesia. http://digilib.uinsby.ac.id/30299/

Palmer, S. (2011). Konseling dan Psikoterapi. Pustaka Pelajar.

Putra, I. (2016). Yes-Set Conditioning. Sertifikasi Neo NLP, Trawas.

Rahman, A. (2010). Pengembangan Pegawai melalui Perencanaan Pelatihan yang Efektif. Jurnal Borneo Administrator, 6(2), 1-17.

Ramayulis. (2016). Psikologi Agama (11th ed.). Kalam Mulia.

Rambe, M. S., \& Yarni, N. (2019). Pengaruh Gaya Belajar Visual, Auditorial dan Konestetik Terhadap Prestasi Belajar Siswa SMA Dian Andalas Padang. Jurnal Review Pendidikan Dan Pengajaran, 2(2), 291-286.

Rasmun. (2004). Stress Koping dan Adaptasi. Salemba Humanika.

Sabati, F. (2017). Hubungan antara Tingkatan Berpikir Positif dengan Kecemasan Berkomunikasi Mahasiswa. Psychopolitan, 1(1), 31-38.

Saleh, H., \& Warsito. (2019). Peningkatan Kemampuan Koneksi Matematis Mahasiswa Melalui Pembelajaran Model Siklus 7E Berbantuan Hypnotheaching. Prima: Jurnal Pendidikan Matematika, 3(2), 158-174.

Sheoran, P. (2016). Effectiveness of NLP in Dealing with Guilt Induced Anxiety, Depression and Stress: A case Study. The International Journal of Indian Psychology, 4(1), 147-156.

Soh, A. S. (2015). Turbo Speed Hipnotis. Spasi Media.

Sugiono. (2019). Metode Penelitian \& Pengembangan. Alfabeta.

Triana, K. D. L., \& Yanti, N. P. E. D. (2018). Neuro-Linguistic Programming: Solusi Tingkatkan Self-Efficacy Perawat di Rumah Sakit. Bimiki, 6(2), 18-27.

Wikanengsih. (2012). Menerapkan Neurolinguistic Programming (NLP) dalam Pembelajaran. Semantik, 1(1), 31-45.

Zeig, J. K. (1980). Symptom prescription and Ericksonian principles of hypnosis and psychotherapy. American Journal of Clinical Hypnosis, 23(1), 16-22. 